\title{
Molecular Crowding and a Minimal Footprint at a Gold Nanoparticle Support Stabilize Glucose Oxidase and Boost its Activity
}

\author{
Yuanmo Wang, ${ }^{\dagger}$ Rima Jonkute, ${ }^{\dagger}$ Hampus Lindmark, ${ }^{\dagger}$ Jacqueline D. Keighron, ${ }^{\ddagger}$ and \\ Ann-Sofie Cans*,t \\ ${ }^{\dagger}$ Department of Chemistry and Chemical Engineering, Chalmers University of Technology, \\ Kemigården 4, SE-412 96 Gothenburg, Sweden \\ ${ }^{\ddagger}$ Department of Chemical and Biological Sciences, New York Institute of Technology, Old Westbury, \\ NY 11568, USA
}

KEYWORDS: Glucose Oxidase, gold nanoparticles, enzyme monolayer, retained enzymatic activity, molecular crowding, enzyme footprint, ultrafast biosensor

\section{Supporting Information Placeholder}

\begin{abstract}
Enzymes conjugated to nanomaterials are used in the design of various biotechnologies. In development of biosensors, surface modifications with the enzyme glucose oxidase (GOx) serve to aid the detection of blood glucose. In order to optimize sensor effectiveness, the enzyme tertiary structure needs to be preserved upon immobilization to retain the enzyme's catalytic activity. Due to the nature of GOx, it suffers from a tendency to denature when immobilized at a solid surface, methods to optimize enzyme stability are of great importance. Here, we introduce the study of the interaction of GOx to the highly curved surface of $20 \mathrm{~nm}$ gold nanoparticles (AuNP) that shows how placing a monolayer of enzyme where the enzyme spreads thin at the AuNP surface still provides stable catalytic performance up to the 14 days compared to enzymes free in solution. Moreover, by increasing enzyme density and creating a molecularly crowded environment at the highly curved nanoparticle surface, which limits the size of the enzyme footprint for attachment, the activity per enzyme can be enhanced up to $300 \%$. This is of great importance for implementing stable and sensitive sensor technologies that are constructed by enzyme-based nanoparticle scaffolds. Here, we show by using the conditions that maintain GOx structure and function when limiting the enzyme coating to an ultrathin layer, the design and construction of ultrafast responding diagnostic sensor technology for glucose can be achieved, which is crucial for monitoring rapid fluctuations of, for instance, glucose in the brain.
\end{abstract}

\section{INTRODUCTION}

The enzyme and its catalytic function plays an important role in a number of application areas, such as environmental sciences, manufacturing processes, biochemical sciences and pharmaceutical industry. ${ }^{1,2}$ In order to benefit from the catalytic properties of the enzyme in these technical solutions it is usually required that the enzyme be bonded to a surface. Once the enzyme is immobilized, it is important that enzymatic activity is maintained. Therefore, when enzymes are used for technical purposes, it is of great importance to avoid enzyme deformation, which often alters its physicochemical properties and in turn affect its biological function.

Glucose oxidase (GOx) is an enzyme that is widely used in biosensor designs for sensing of blood glucose concentration from diabetes patients. GOx is an ideal enzyme for this purpose due to its relative high stability, catalytic turnover and specificity. ${ }^{3}$ In the presence of oxygen, GOx catalyzes the oxidation of $\beta$-D-glucose to form hydrogen peroxide $\left(\mathrm{H}_{2} \mathrm{O}_{2}\right)$ and D-glucono- $\delta$ lactone that further spontaneously hydrolyzes to gluconic acid. GOx maintains its enzymatic activity within a broad $\mathrm{pH}$ range that spans between $\mathrm{pH}$ 2-8 depending on origin of strain. ${ }^{4}$ 
Hence GOx is a very suitable enzyme for use in sensor design of probing glucose concentrations under physiological conditions. However, GOx is an enzyme that tends to attach and spread when immobilized to solid surfaces. The enzyme having bulk dimensions of about $5 \times 7 \times 8 \mathrm{~nm},{ }^{4-10}$ shows tendencies to flatten from its original shape when adsorbing to a flat surface and thereby altering the dimensions to about 14-18 nm in length, 5-8 $\mathrm{nm}$ in width and a $0.5-2 \mathrm{~nm}$ in thickness depending on the surface material for immobilization. , $10-12$ This leads to significant enzyme conformational changes and often result in significant loss of the enzyme activity upon denaturation. ${ }^{13}$

To minimize denaturation during immobilization at surfaces, studies have showed that highly concave or convex surfaces are protective to certain enzymes when immobilized. ${ }^{13,14}$ Previous studies show that enzyme structure and function may be retained when immobilized into nanopores or onto nanoparticle surfaces and sometimes even display improvement in the enzymatic activity after immobilization compared to enzyme in native state. ${ }^{15-19}$ Therefore, enzymes bound to the surface of nanostructured material can offer enhanced sensing schemes when implementing this scaffold in electrochemical biosensor designs. ${ }^{20-23}$ Implementing nanomaterial at sensor surfaces is also beneficial to sensor sensitivity by offering a larger sensor surface area and additionally, if the immobilized enzymes are limited to create an ultra-thin layer rather than the more conventional thicker layers, the temporal resolution of such probe can be improved multi-fold and the consumption of enzymes can be minimized during the fabrication process. ${ }^{24-26}$ However, the enzyme surface interactions for different materials are not general for enzymes, and therefore surface interactions for each individual type of enzyme needs to be studied independently. In addition, the enzyme dimensional changes when adsorbed onto colloidal surface materials have been drawn limited attention.

In this study, we have focused on studying the interaction of GOx to the highly curved surface of $20 \mathrm{~nm}$ AuNPs and investigating what conditions allows GOx to maintain its stability after immobilization to the nanostructured surface, while also limiting the enzyme coating to a monolayer. Optimizing enzyme activity while consuming minimal amount of enzyme is of high value for glucose biosensors performance as well as fabrication costs, while minimizing the thickness of the enzyme layer is important in development of biosensors that require high recording speed. ${ }^{24,26,27}$ Here applications such as monitoring metabolic changes of blood glucose in brain tissue is of great importance, as such high temporal technology is currently lacking. To establish and control the coverage of GOx to a monolayer and to verify potential macromolecular shape changes after enzyme adsorption as well as to evaluate the retained enzyme activity after enzymes had been immobilized onto the AuNP support, a variety of analytical techniques were used to characterize the GOx:AuNP conjugates formed. A flocculation assay was used together with a fluorescence-based quantification assay to count the resulting number of enzymes bound when achieving a fully enzyme-covered AuNP surface after the conjugation process. Dynamic light scattering (DLS) and nanoparticle tracking analysis (NTA) was used to monitor the resulting GOx-AuNP conjugate size and to estimate the molar ratio of GOx-to-AuNP required to prevent GOx from losing its original conformation. After these optimum conditions for constructing stable conjugates was determined, the retained enzymatic activity of the enzyme-AuNP conjugates and the enzyme stability with time were investigated. The results of this study show that at lower enzyme-to-AuNP ratios enzyme spread out into a thin coating at the surface, whereas at higher enzyme ratios a fully crowded enzyme monolayer coverage is formed and where the enzyme maintains its original bulk dimensions. The activity assay of these conjugates where enzymes attached by a minimal footprint to the AuNP surface showed that the enzyme is physically stabilized and that the retained specific enzyme activity is enhanced multi-fold compared to enzyme activity at bulk conditions. Hence, this study shows the importance of careful characterization of how the enzyme is affected by crowding conditions and interaction to specific surface, which will be used for technological purposes that rely on stable and reliable enzyme catalysis.

\section{EXPERIMENTAL SECTION}

Materials. Alexa Fluor ${ }^{\circledR} 488$ protein labeling kit was purchased from Invitrogen (Carlsbad, CA). Glucose Oxidase (E.C. 1.1.3.4) type X-S from Aspergillus niger (G7141, optimal pH $5.0 \sim 7.0$, optimum temperature $40{ }^{\circ} \mathrm{C} \sim 60{ }^{\circ} \mathrm{C} \dot{i},{ }^{3,28}$ horseradish peroxidase (HRP) type $\mathrm{VI}$ from horseradish roots, sodium chloride $(\mathrm{NaCl})$, sodium bicarbonate $\left(\mathrm{NaHCO}_{3}\right)$, potassium cyanide $(\mathrm{KCN})$, potassium chloride $(\mathrm{KCl})$, phosphate-buffered saline (PBS) tablets (10 mM, pH 7.2), sulfuric acid $\left(\mathrm{H}_{2} \mathrm{SO}_{4}\right)$, copper sulfate $\left(\mathrm{CuSO}_{4}\right)$, gold chloride trihydrate $\left(\mathrm{HAuCl}_{4} \cdot 3 \mathrm{H}_{2} \mathrm{O}\right)$, ferrocene-methanol (FcMeOH), O-Phenylenediamine (OPD) and Whatman ${ }^{\circledR}$ Anotop $^{\circledR} 25$ syringe filters with $20 \mathrm{~nm}$ filtering size were purchased from Sigma-Aldrich (St. Louis, MO, USA). $20 \mathrm{~nm}$ AuNP colloidal solution was purchased from BBI Solutions (Cardiff, U.K.). 1,2-dioleoyl-sn-glycero-3phosphocholine (DOPC), 1,2-dioleoyl-sn-glycero3-phosphoethanolamine (DOPE) and cholesterol were purchased from Avanti Polar Lipids Inc., 
U.S.A. MilliQ water with resistivity $\mathrm{M} \Omega . \mathrm{cm}$ was used in all experiments.

Theoretical calculations estimate the number of GOx needed to fully cover the AuNP surface. To characterize the GOx in terms of macromolecular shape changes after adsorbing to the surface of AuNPs, theoretical calculations of the estimated maximum number of GOx that can fit at the surface of a $20 \mathrm{~nm}$ AuNP while keeping the original dimension of the enzyme were performed using published data on GOx size and calculated for the different geometrical ways enzymes can pack onto the AuNP surface (Figure 1B).

As shown in Figure $1 \mathrm{~A}$, to determine the size of the enzyme footprint area, $A_{E}$, which defines the surface area occupied by each single enzyme when bound to the AuNP surface, calculations were first performed using the average dimensions of GOx enzyme when approximated to a spherical shape:

$$
A_{E}=\pi r_{E}^{2}(1)
$$

where $r_{E}$ is the radius of the enzyme, and was followed by calculations considering the enzyme with an elliptical shape: $A_{E}=\pi a b(2)$

where $a$ is the semimajor axis, $b$ is the semiminor axis of the enzyme. Considering the available surface area of the AuNP, $A_{\text {AuNP, }}$ for GOx to bind, the maximum number of GOx that theoretically can fit and fully cover the available surface area of a $20 \mathrm{~nm}$ AuNP depending of average shape and direction for the enzyme to bind to the AuNP surface was then estimated:

$$
\text { Number of GOx per } A u N P=\frac{A_{E}}{A_{A u N P}}(3)
$$
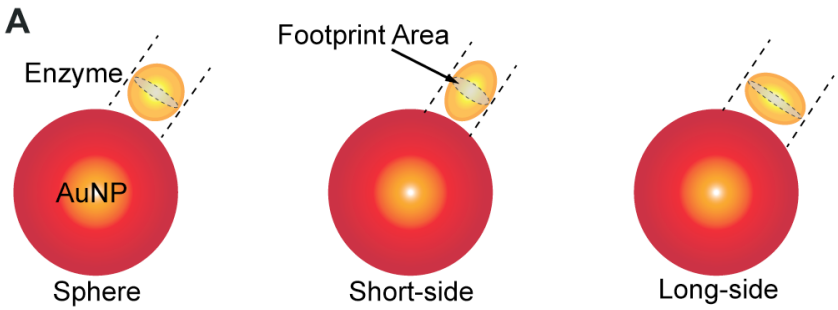

B

\begin{tabular}{c|c|c|c}
\hline GOx shape & Dimensions of GOx & Position & GOx/AuNP \\
\hline Sphere & $* 7.0 \mathrm{~nm}^{9}$ & Random & 33 \\
\hline \multirow{2}{*}{ Ellipsoid } & \multirow{2}{*}{$6.0 \mathrm{~nm} \times 5.2 \mathrm{~nm} \times 7.7 \mathrm{~nm}^{4}$} & Short side & 51 \\
\cline { 3 - 4 } & & Long side & 35 \\
\hline \multirow{2}{*}{ Ellipsoid } & \multirow{2}{*}{$7.0 \mathrm{~nm} \times 5.5 \mathrm{~nm} \times 8.0 \mathrm{~nm}^{7}$} & Short side & 42 \\
\cline { 3 - 4 } & & Long side & 29 \\
\hline
\end{tabular}

*Hydrodynamic diameter

Figure 1. Estimation of the number of enzymes that can fit and fully cover the surface of an AuNP. (A) Illustration of cases when considering the enzyme shape as a sphere, an elliptical shaped macromolecule attaching by its short-side and an elliptical enzyme attaching by its long-side.
Mathematic calculation of the number of GOx that can fully cover the surface of a $20 \mathrm{~nm}$ AuNP at different dimension size. Schematics are not drawn to scale.

Preparation of GOx-AuNP conjugates. The GOx-AuNP conjugates were prepared by allowing GOx to self-adsorb to the AuNP surface. The binding interaction between the negatively charged GOx and AuNP surfaces can be related to many collective week forces such as van Deer Waals forces, hydrogen bonds, hydrophobic interactions, but covalent thiol bonds at one of the cysteine rich side of GOx has also shown to contribute by strong binding affinity to gold. ${ }^{29-32}$ For creating GOx-AuNP conjugates with varying enzyme-to-AuNP molar ratios, different size aliquots from a $2 \mathrm{mg} / \mathrm{ml} \mathrm{GOx}$ stock solution in 10 $\mathrm{mM} \mathrm{NaHCO}$ buffer, pH 8.2 was added to a fix volume of $1 \mathrm{nM}$ AuNP solution in $2 \mathrm{ml}$ Maxymum Recovery ${ }^{\circledR}$ centrifuge tubes (Maxyclear Boil Proof, VWR, USA). The final volume of the conjugate samples was adjusted with $\mathrm{NaHCO}_{3}$ buffer solution and was incubated in the dark, at room temperature for 1.5 hours. After the conjugation process, GOx:AuNP conjugates were isolated by centrifugation at $10621 \mathrm{~g}$ for 30 minutes at $4 \quad{ }^{\circ} \mathrm{C}$. The supernatant containing unbound GOx was carefully removed and transferred into separate new centrifuge tubes for later indirect enzyme quantification measurements. A volume of $50 \mu$ l containing the pelleted GOx-AuNP conjugates was left in the bottom of the tube followed by resuspension into $10 \mathrm{mM} \mathrm{NaHCO}$ buffer replacing the same volume as the extracted supernatant. The process of cleaning procedure of resuspending the pelleted conjugates in fresh $10 \mathrm{mM} \mathrm{NaHCO}$ buffer after centrifugation was repeated two times, and the supernatant from each cleaning procedure was collected and saved. In samples where lower amounts of enzyme was added during the conjugation process, AuNPs that remained uncoated or partially coated would aggregate and stick to the wall of the test tubes and hence was eliminated for further analysis.

Flocculation assays. To determine the ratio of enzyme-to-AuNP needed in solution to fully cover the AuNP surface during the enzyme AuNP conjugation process, a flocculation assay was conducted. ${ }^{14,33}$ Briefly, the assay was designed by preparing samples containing GOx-AuNP conjugates with a variety of different enzyme-toAuNP ratio. To each sample a solution of $\mathrm{NaCl}$ was added to a final concentration of $0.2 \mathrm{M}$. The high salt solution reduces the electric double layer at the AuNP surface, which destabilizes the colloids in solution. Hence, if insufficient amount of enzyme is covering the AuNP surface, the colloids aggregate in solution. However, if enough enzyme is coating the AuNP surface creates a steric hindrance for the AuNP, which prevents particle aggregation. This process can be monitored using UV-Vis spectroscopy as 
sufficiently protected GOx-AuNP conjugates display a plasmonic peak overlapping the peak wavelength of $524 \mathrm{~nm}$ for bare $20 \mathrm{~nm}$ AuNPs, serving as a reference sample, (Figure 3A), whereas aggregates formed from insufficiently protected AuNP shift to the red spectrum. Therefore, after 20 minutes incubation time of samples in high salt solution and in the dark, an absorbance spectrum between $400 \mathrm{~nm}$ and 800 $\mathrm{nm}$ was measured using a Cary 4000 and Cary 5000 UV-Vis spectrophotometer (Agilent Technologies, USA) and a Hellma quartz suprasil cuvette QS $10 \mathrm{~mm}$ as a UV-Vis sample container. By monitoring the individual UV-Vis spectra of the conjugate samples, the minimal amount of enzymes needed to fully cover the AuNP surface can be determined from the spectra where a full peak overlap with bare AuNP in Milli-Q water is achieved.

Enzyme labeling. For the fluorescent quantification assay GOx was pre-labeled with an Alexa Fluor $^{\circledR} 488$ dye using an Alexa Fluor $^{\circledR} 488$ Protein Labeling Kit provided by Invitrogen. Briefly, a $2 \mathrm{mg} / \mathrm{mL}$ GOx solution was prepared in $0.1 \mathrm{M} \mathrm{NaHCO}_{3} \mathrm{pH} 8$, and was incubated with the Alexa Fluor ${ }^{\circledR} 488$ dye for an hour in the dark while stirring. Fluorescent tags that remained nonbound were separated from the enzyme using a size exclusion separation column, provided by the kit. The protein concentration and degree of fluorophore labeling was determined according to the protocol and extinction coefficients according to the labeling kit.

Indirect and direct quantification of enzyme bound to the AuNP surface. To experimentally determine the number of enzymes attached to the surface of AuNP, fluorescently labeled GOx were used in the conjugation process and both an indirect and a direct quantification method was implemented in parallel. The indirect method was performed by fluorescence quantification of the non-bound enzymes collected from the supernatant solution after centrifugation cleaning step of the newly synthesized GOx-AuNP conjugates using a Cary Eclipse Fluorescent Spectrophotometer (Agilent Technologies, USA). For each sample calculations were performed relating the amount enzyme measured free in solution versus the amount added during the conjugation process to determine the amount of enzymes bound to the AuNP surface. A new calibration curve of the labeled GOx was performed for each new batch of labeled enzymes and for each new assay that was performed.

In the direct quantification method, the amount of GOx immobilized onto the AuNP surface was determined by subjecting the GOx-AuNP conjugates after the centrifugation cleaning step to KCN which dissolves the AuNP and free the enzymes bound into solution. This was performed by adding $50 \mu \mathrm{L}$ freshly made $25 \mathrm{mM} \mathrm{KCN}$ to 200 $\mu \mathrm{L}$ conjugate pellet solution followed by half an hour incubation of samples in the dark. In process, the sample solutions transferred from a red color to completely optical clear as the colloidal particles fully dissolved. The free GOx in solution was then quantified using fluorimetry. To determine the average number of enzymes per AuNP, the amount of immobilized GOx was correlated to the number of non-aggregated AuNP in each sample solution. Therefore, for each sample, quantification of AuNP was performed using a previously established spectroscopybased method. ${ }^{34}$ This method applies for a $20 \mathrm{~nm}$ AuNP by measuring the absorbance at $450 \mathrm{~nm}$ and was performed using a Cary 4000 and Cary 5000 UV-Vis spectrophotometer. The AuNP concentration was then calculated according to Equation 4:

$$
N=\frac{A_{450} \times 10^{14}}{d^{2}\left[-0.295+1.36 \exp \left(-\left(\frac{d-96.8}{78.2}\right)^{2}\right)\right]^{(4)}}
$$

where $d$ is the diameter of the AuNP and $\mathrm{A}_{450}$ is the absorbance of the conjugates at $450 \mathrm{~nm}$. The average number of enzyme per particle in each sample was thereafter calculated both using the indirect and direct quantification of enzyme bound at AuNP surfaces and was then related to the measured number of non-aggregated AuNP in solution, to provide an average amount of $\mathrm{GOx}$ adsorbed per AuNP in each sample.

Dynamic light scattering (DLS) measurements of conjugate size. To monitor the resultant conjugate size when varying the number of enzymes added during the AuNP conjugation process, the hydrodynamic diameter ( $D_{\text {hyd }}$ ) of AuNPs and GOx-AuNP conjugates was measured using a Zetasizer Nano ZS (Malvern Instruments Ltd, UK) which was equipped with a $\mathrm{He}-\mathrm{Ne}$ laser $(633 \mathrm{~nm})$ as a light source. Disposable, small volume $(70 \mu \mathrm{L})$ BRAND ${ }^{\circledR}$ cuvettes (BRAND GMBH + CO KG, Germany) were used during measurement. For each sample, three measurements were performed with recording of 12-15 runs for every measurement. All size measurements were detected using the backscatter detection with angle of $173^{\circ}$ at room temperature. Zetasizer Software 7.10 was used to analyze all the data and the reported values were based on Z-average size that is an intensity mean via cumulate analysis. The DLS measurements were carried out 6 hours after GOx-AuNP conjugation process. To eliminate artifacts during measurement the $\mathrm{NaHCO}_{3}$ buffer solution was filtered using a $20 \mathrm{~nm}$ syringe filters before use.

Nanoparticle tracking analysis (NTA) measurements of conjugate size. Colloidal size measurements were also performed using a Malvern NanoSight LM10 (Malvern Instruments 
Ltd, UK), configured with a temperaturecontrolled sample chamber with a $488 \mathrm{~nm}$ (blue) laser and a highly sensitive C11440-50B/A1189302 sCMOS camera (Hamamatsu Photonics K.K., Japan) to track scattered light of individual AuNPs and GOx-AuNP conjugates. NTA 3.1 software was used for performing 5 runs of $60 \mathrm{~s}$ video recording capturing the colloidal particles under Brownian motion that was further used for analysis and determining the average particle size. All measurements were performed at room temperature and immediately after the three-step centrifugation cleaning process of the GOx-AuNP conjugates and 6 hours after the GOx-AuNP conjugation process. To eliminate artifacts in the measurement the $\mathrm{NaHCO}_{3}$ buffer was filtered with $20 \mathrm{~nm}$ syringe filters before use.

Enzyme activity assay. To determine the level of retained enzyme activity after immobilization of GOx to the AuNP surface, versus the enzymatic activity of GOx free in solution, a UV-Vis spectrophotometer-based assay was used. As shown by the catalytic reactions in Figure 2, in this assay glucose, the enzymatic substrate for $\mathrm{GOx}$, is first catalyzed to form the enzymatic product gluconic acid and $\mathrm{H}_{2} \mathrm{O}_{2}$. Subsequently, in the presence of o-phenylenediamine (OPD) and the additional enzyme, $\mathrm{HRP}, \mathrm{H}_{2} \mathrm{O}_{2}$ is converted to produce 2,3-Diaminophenazine (DAP) that can be spectrophotometrically can be quantified by measuring the absorbance at $492 \mathrm{~nm}$ and using Lambert-Beers law and the molar absorptivity coefficient for DAP at $429 \mathrm{~nm}, \quad \varepsilon_{492}=67143 \mathrm{M}^{-1}$ $\left.\mathrm{cm}^{-1}\right) .{ }^{14}$

$$
\begin{aligned}
& \text { Glucose }+\mathrm{O}_{2} \stackrel{\mathrm{GOx}}{\longrightarrow} \text { Gluconic acid }+\mathrm{H}_{2} \mathrm{O}_{2} \\
& \mathrm{H}_{2} \mathrm{O}_{2}+\text { OPD } \stackrel{\mathrm{HRP}}{\longrightarrow} \text { DAP }+4 \mathrm{H}_{2} \mathrm{O} \\
& \text { Abs } 492 \mathrm{~nm}
\end{aligned}
$$

Figure 2. The reaction schemes for the sequential enzymatic reactions where the assay for monitoring GOx activity, glucose is converted to DAP and detected using spectrophotometry at $492 \mathrm{~nm}$.

The enzyme activity assays were performed using conjugates prepared from adding a 100:1 molar ratio GOx-to-AuNP during the conjugation process. Prior to each GOx activity assay, HRP and OPD solutions were freshly made in $10 \mathrm{mM}$ PBS pH 7.4 before use. Briefly, the assay was designed to add $100 \mu \mathrm{L}$ of $3.15 \mathrm{nM}(0.5 \mu \mathrm{g} / \mathrm{ml})$ GOx solution, $100 \mu \mathrm{L}$ of $25 \mathrm{nM}(1.1 \mu \mathrm{g} / \mathrm{ml}) \mathrm{HRP}$ solution, $100 \mu \mathrm{L}$ of $125 \mathrm{nM}$ OPD solution and 80 $\mu \mathrm{L}$ of $10 \mathrm{mM}$ PBS solution into each well of a 24well plate. At the moment of adding $20 \mu \mathrm{L}$ of 250 nM glucose solution, time was immediately counted. After 20 seconds, $100 \mu \mathrm{L}$ of $3 \mathrm{M} \mathrm{HCl}$ was used to stop the enzymatic reaction. The DAP product formation was measured by monitoring the absorbance of samples at $492 \mathrm{~nm}$ wavelength using a spectrophotometer. The experimental assay conditions on molar ratio of glucose, glucose oxidase and reaction time were optimized to ensure a substrate concentration range used was below the concentration for substrate inhibition ${ }^{35-37}$ and that was optimized to achieve a maximal reaction rate. These experiments must be operated in the dark at room temperature and within a short time frame since HRP and OPD are both sensitive to light and OPD can auto-catalyze into product formation of DAP. The enzyme activity for both immobilized and free GOx was calculated using Equation 5.

$$
\text { Specific activity }=\frac{n_{D A P}}{t \times m_{G O x}}\left(\mu \mathrm{mol} \min ^{-1} \mathrm{mg}^{-1}\right)(5)
$$

where $n_{D A P}$ is the amount of produced DAP in moles, $t$ is the reaction time in minutes, and $m_{G O x}$ is the mass of GOx added into the reaction.

In these assays comparing the activities of free GOx and immobilized GOx, enzyme stability was also investigated by compared the enzyme activity from day 0 to the activity of enzyme conjugates and free enzyme with continuous intervals until 14 days after the conjugation process was first initiated.

Glucose liposome preparation. The glucose liposome were prepared by adding DOPC, DOPE and cholesterol solutions at molar ratio 39:21:40 into a round flask with stir under $\mathrm{N}_{2}$ gas for three hours to form a thin lipid film onto the internal wall of flask. Glucose liposome were made by rehydrating the lipid film with $200 \mathrm{mM}$ glucose solution dissolved in $10 \mathrm{mM}$ HEPES ( $\mathrm{pH} 7.4,236$ $\mathrm{mOsm} / \mathrm{kg}$ ) for $30 \mathrm{~min}$ at room temperature with an approximately final concentration of 1.25 $\mathrm{mg} / \mathrm{ml}$ for total lipids. The harvested liposome solution went through five cycles of freeze-thaw by alternately placing into liquid nitrogen and water at room temperature to completely entrap glucose into liposome. ${ }^{38}$ The size of liposome was unified by extruding liposome suspension through a polycarbonate membrane with $400 \mathrm{~nm}$ pore size (Whatman, USA) 21 times under a constant pressure ( 1 bar) from $\mathrm{N}_{2}$ gas at room temperature with support of Avanti Mini-Extruder (Avanti Polar Lipids, Inc., USA). The unloaded glucose suspended outside of liposome were removed by illustra $^{\mathrm{TM}}$ Microspin $^{\mathrm{TM}}$ S-200 HR columns (GE Healthcare, Buckinghamshire, U.K.). The osmotic pressure of dilution solution needed for later electrochemical measurement was adjusted to $236 \mathrm{mOsm} / \mathrm{kg}$ by dissolving $\mathrm{NaCl}$ in $10 \mathrm{mM}$ HEPES (pH 7.4).

Amperometric measurements of ultrafast glucose biosensor using glucose liposome. The glucose biosensors were made by inserting each $33 \mu \mathrm{m}$ (in diameter) carbon fibers into single borosilicate glass capillaries with $1.2 \mathrm{~mm}$ outer diameter and $0.69 \mathrm{~mm}$ inner diameter (Sutter 
Instrument Co., Novato, CA, USA). A micropipette puller (model P-1000, Sutter Instrument Co., Novato, USA) was then used to pull the carbon fiber filled glass capillary from the middle into two electrodes with fine tapered tips. All electrode tips were put into the epoxy solutions (EpoTek 301, Epoxy Technology, Billerica, MA, USA) with afterwards incubation at $100{ }^{\circ} \mathrm{C} \in$ oven in air overnight to seal the glass-carbon junction. Each electrode tips were examined and cut close to the carbon-glass junction using scalpel under microscope. To achieve a glass-sealed disc carbon surface, micropipette beveller (model BV-10, Sutter Instrument Co., Novato, USA) was used to polish the tip surface at $45^{\circ}$. Only electrodes achieved a steady state current in the cyclic voltammetry measurement were used for later sensor fabrication via tip surface modification. Cyclic voltammetry was performed by putting carbon electrodes (backfilled with $3 \mathrm{M} \mathrm{KCl}$ solution and a tungsten wire as connection) into $1 \mathrm{mM}$ $\mathrm{FcMeOH}$ versus a saturated $\mathrm{Ag} / \mathrm{AgCl}$ reference electrode ( $\mathrm{CH}$ Instruments, USA) and scanning at $0.1 \mathrm{Vs}^{-1}$ between $-0.2 \mathrm{~V}$ and $+0.8 \mathrm{~V}$ using $\mathrm{a}$ potentiostat (model 650A Series MultiPotentiostat, $\mathrm{CH}$ Instruments, USA).

The electrode tip surface was fabricated with 20 $\mathrm{nm}$ (in diameter) AuNP hemispheres via electrochemical deposition as reported in our recent study. ${ }^{24,26}$ The surface area of deposited AuNP was electrochemically determined by firstly obtaining surface charge of AuNP via a linear sweep at a rate of $0.1 \mathrm{Vs}^{-1}$ from $+1.4 \mathrm{~V}$ with holding for $5 \mathrm{~s}$ to $+0.5 \mathrm{~V}$ in $500 \mathrm{mM} \mathrm{H}_{2} \mathrm{SO}_{4}{ }^{24}$ and integration the of the resulted peak at approximate $+0.8 \mathrm{~V}$, and by afterward dividing Au surface charge density $489 \mu \mathrm{C} \mathrm{cm}^{-2}$ 39. GOx were immobilized onto the AuNP surface at molar ratio of GOx:AuNP 8000:1 via self-adsorption by dipping the tip of AuNP coated carbon electrodes into the GOx solution that was freshly made by 10 $\mathrm{mM}$ sodium bicarbonate $(\mathrm{pH}$ 8.2) for approximate 2 hours at room temperature. All glucose sensors were used immediately after fabrication.

After putting glucose sensor (working electrode) and a chlorinated $\mathrm{Ag}$ wire (reference electrode) into glucose liposome solutions, the sensor's response speed was measured via amperometric recordings by holding $0 \mathrm{mV}$ onto sensor for $15 \mathrm{~s}$ and changing down the potential down to -500 $\mathrm{mV}$ for 3-5 min using a HEKA patch clamp amplifier (EPC 10, HEKA elektronik, Lambrecht, Germany) at room temperature. The signal was recorded at $20 \mathrm{kHz}$ and Bessel filtered at $10 \mathrm{kHz}$. The amperometric data were analyzed by a program from David Sulzer's group ${ }^{40}$ in IgorPro 6.37 software (WaveMetrics, Lake Oswego, OR, U.S.A.), they were firstly smoothed to $5 \mathrm{kHz}$ (binomial sm.), and detected as a responding spike when more than 5 times of the standard deviation of the derivative of baseline current at 0 $\mathrm{mV}$ with respect to time.

\section{RESULTS AND DISCUSSION}

Although specific sensor requirements differ between applications, improving the interaction between an enzyme and the surface it is immobilized to is essential for producing stable biosensors with good catalytic turnover. GOx is of specific interest to the design of biosensors used to detect glucose in complex matrices such as blood. However, GOx has been reported in literature to denature upon adsorption to flat surfaces, reducing its catalytic turnover and limiting its usability in biosensors that require high spatial and temporal resolution. In an optimized design, enzymes will be densely packed into a monolayer coating on the biosensor surface to create an environment where (1) each enzyme is accessible to solution so that substrates may bind, and (2) catalytic products can easily and quickly diffuse to the area of detection. In this work we used highly curved 20 $\mathrm{nm}$ AuNP to immobilize GOx to prevent the denaturation found with flat surfaces. ${ }^{13}$ An extensive characterization of the GOx:AnNP interaction was conducted to find the optimal conditions for retained catalytic activity, and finally, these optimized conditions were tested in a biosensor design shown previously to provide excellent temporal and spatial resolution..$^{24-26}$

Flocculation assays reveal AuNP surfaces are completely coated with GOX at a GOx:AuNP ratio of 50:1. In order to characterize the interactions between GOx and $20 \mathrm{~nm}$ AuNP we conducted flocculation assays to determine the point at which the AuNP surface can be completely coated with enzyme. Figure 3A illustrates how a flocculation assay is conducted. Initially, AuNP is incubated with GOx in solution and protected from light. Over the course of 90 min GOx self-adsorbs onto the surface of the AuNP creating a physical barrier to salt-induced flocculation. When a sufficient amount of GOx is present, the steric hindrance of the enzyme layer prevents the aggregation of AuNP that would otherwise take place when there is no longer sufficient charge repulsion between nanoparticles. 
A
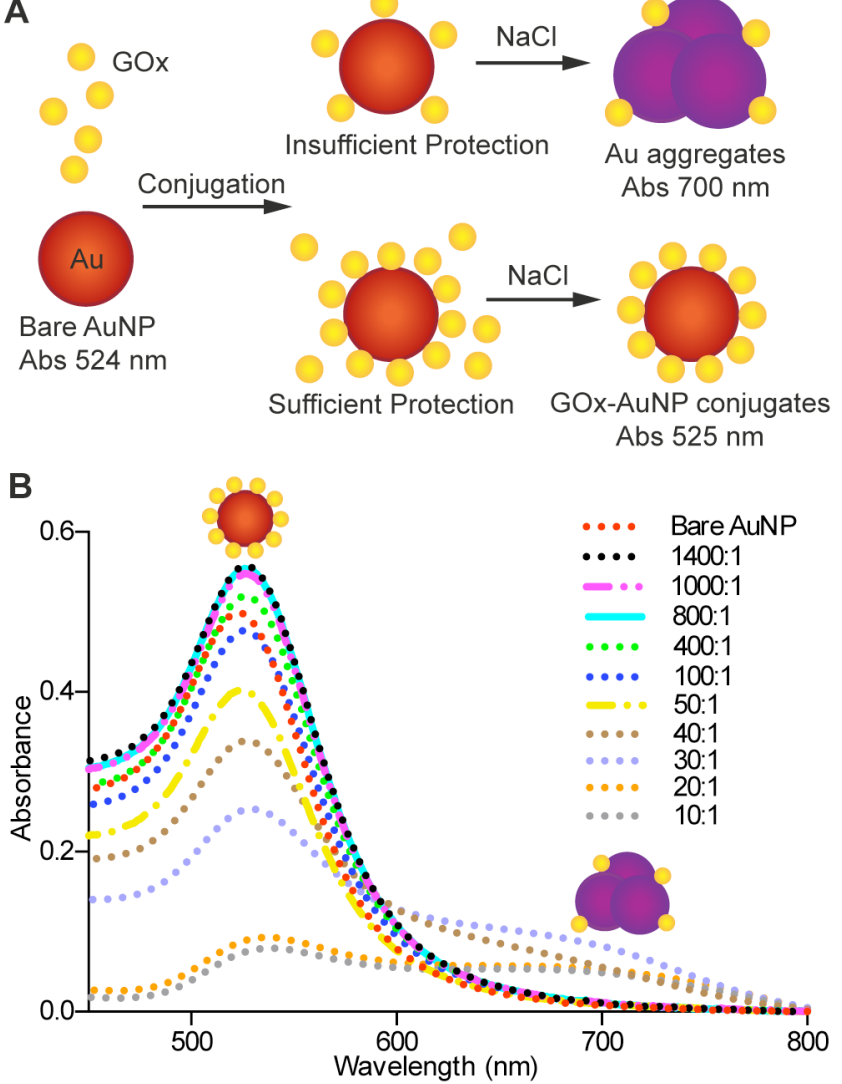

Figure 3. (A) Schematic of a flocculation assay showing that by adding low amount of GOx, few enzymes immobilize at the AuNP surface and in a high salt environment the insufficiently enzyme protected conjugates will aggregate. Whereas if a high amount of enzyme is added, the conjugates are stable in high salinity solution. The aggregated versus stable conjugate states can be distinguished by the difference in their absorption spectrum. (B) The absorption spectra from a flocculation assay showing if a complete (plasmonic peak at $524 \mathrm{~nm}$ ) or incomplete (redshifted peak) coating of enzyme has been formed at the AuNP surface after varying the ratio of GOx:AuNP added in the conjugation process. Schematics are not drawn to scale.

UV-Vis spectrophotometry was used to monitor the changes in the surface plasmon resonance of the AuNP. Bare $20 \mathrm{~nm}$ AuNP has an absorption maximum of $524 \mathrm{~nm}$ when exposed to flocculation inducing high-salt concentrations the absorption maximum is shifted dramatically to longer wavelengths as the plasmon resonance shifts with nanoparticle aggregates. GOx-AuNP conjugates, which are sufficiently protected from aggregation will display absorption spectra similar to that of bare AuNP, with a maximum close to $524 \mathrm{~nm}$, indicating that no aggregation has occurred. Figure 3B summarizes how adding a range of different amount of enzyme vs AuNP, ranging from GOx:AuNP ratios of 10:1 to 1400:1, during the conjugation process result in a fully vs a not fully enzyme covered surface. Results indicate that ratios of 50:1 and above were capable of preventing salt induced flocculation.
As summarized in the Figure 1B, theoretical estimates of the number of GOx necessary to fully coat the AuNP surface ranged between 29:1 and 51:1 depending on the reported size of GOx and the direction for enzyme to bind. ${ }^{4,7,9}$ According to our flocculation experimental results suggesting a minimum ratio of 50:1 of GOx:AuNP is necessary in solution during conjugation to eliminate aggregates forming, while also considering the amplitude of the AuNP plasmonic peak suggest that a 100:1 or higher ratio is needed to completely coat and producing a monolayer of GOx on the surface of the AuNPs in the sample solution. GOx has been shown to contain a cysteine rich patch containing thiol groups that may create a strong binding affinity for the Au surface, ${ }^{29-32}$ which may direct the binding of GOx to AuNP, but other binding strategies might influence enzyme immobilization. Previous work on examining the interactions between the enzymes horse radish peroxidase and glutamate oxidase, respectively, with the surface of AuNP have found that the enzyme:AuNP ratio necessary to prevent flocculation can vary greatly from theoretical predictions. ${ }^{14,26}$ In those cases, it is assumed that the specific properties of the enzyme play an important role in the self-adsorption process. Due to this phenomenon, the number of enzymes actually bound per AuNP needs to be quantified by directly and indirectly measurements for each specific case.

Conjugate characterization reveals only a monolayer of GOx adsorbs to AuNPs even with high enzyme ratios. Direct and indirect quantification of the number of GOx adsorbed per AuNP after conjugation was performed as shown in Figure 4A. Briefly, GOx was first fluorescently labeled by covalently binding to Alexa Fluor $^{\circledR} 488$ dye. This allowed for the quantification of enzyme concentration based on fluorescent signal. Labeled GOx was then conjugated to AuNP using ratios ranging from 20:1 to 8000:1 of GOx:AuNP. The subsequent conjugates were centrifuged to remove excess enzyme that remained unbound and the unbound enzyme in solution was used for the indirect quantification. The purified conjugate was then subjected to treatment with $\mathrm{KCN}$, which dissolved the AuNP to leave the labeled GOx free in solution for direct quantification via fluorescence. The average number of enzymes bound per AuNP was determined by dividing the concentration of enzyme bound by the concentration of AuNP present after conjugation as quantified using UV-Vis spectrophotometry. As shown in Figure 4B, the number of GOx immobilized per AuNP increases with adding a larger amount of enzyme at conjugation and at the largest ratio of GOx:AuNP added, the number of enzymes attached reach the magnitude which in theory would correspond to a GOx monolayer coating at a $20 \mathrm{~nm}$ AuNP surface. 
Conjugate recovery is dependent on GOx:AuNP ratio. The percent recovery of AuNP with each molar ratio of GOx added was determined by measuring the absorbance at 450 $\mathrm{nm}$ after conjugate preparation and using Equation 4 (Figure 4C). At enzyme ratios at or below what was necessary to fully protect all the available AuNPs from salt induced aggregation, the average conjugate yield was below $40 \%$. At ratios shown to produce conjugates with higher ratios of GOx adsorbed, the yield increased up to a maximum of $75 \%$, suggesting that a greater concentration of AuNP could be completely protected and were prevented from aggregating on the inner wall of the centrifuge tube when excess enzyme was removed. The percent recovery is lower at very high ratios of GOx:AuNP, suggesting that high concentrations of GOx in solution may play a role in AuNP recovery. This data shows a maximum percent recovery with a ratio of 2000:1 GOx:AuNP, and suggests that this ratio be used to get the best yield of conjugates.

At ratios proven to prevent charged induced flocculation of AuNP, 50:1 and above, a minimum of 12 number of GOx per AuNP is shown to be necessary. This ratio is far below the theoretical estimates of enzyme coverage assuming a fully protected AuNP surface area (Figure 1B) and suggests that GOx has denatured to some extent on the AuNP surface, increasing the surface area each GOx molecule covers, likely decreasing its catalytic activity. At higher ratios of 50:1 to 2000:1 that were shown to protect AuNP from salt induced flocculation, the GOx coverage was not found to be significantly higher and at this span of enzyme-to-AuNP ratios the increased amount of GOx mainly first help improve the yield of GOx:AuNP conjugates in solution (Figure 4C). However, as illustrated in Figure 4F, the specific activity of 100:1 GOx:AuNP conjugates was slightly higher than that of the free enzyme in solution, suggesting that the catalytic activity of GOx may be enhanced by adsorption onto a highly curved surface even though significant changes in the tertiary structure may have occurred. Ratios of GOx:AuNP higher than 2000:1 showed an increase in the amount of GOx adsorbed per AuNP. While the coverage of GOx with ratios of $4000: 1$ and $8000: 1$ is significantly increased from that of lower ratios, the ratio found only supports estimates of a densely packed enzyme monolayer coverage even with a large excess of GOx in solution.

The thickness of the GOx layer ( $\left.D_{\text {hyd }}\right)$ at 8000:1 (Figure 4D) was found to be between $2.7 \pm 0.2 \mathrm{~nm}$ (DLS) and $3.8 \pm 1.7 \mathrm{~nm}$ (NTA). This is approximately half the $D_{\text {hyd }}$ found for GOx in solution, ${ }^{9,10}$ however, $D_{\text {hyd }}$ of the AuNP conjugate was found to be significantly greater than previous measurements of GOx adsorbed to flat surfaces. ${ }^{6,10-12}$ The curvature of the AuNP may play an important role in this difference. By using circular dichroism spectroscopy to measure enzyme conformation it was found that enzymes retained significantly more tertiary structure when immobilized to a curved surface than a flat surface. ${ }^{13}$ Hence, the curvature of the scaffold used to immobilize GOx may have a significant impact on the resulting enzyme activity.

GOx specific activity is enhanced by conjugation to AuNP. The specific activity of a single enzyme can be used as an estimate of the catalytic power of an enzyme under varying conditions. Figure $4 \mathrm{~F}$ illustrates the change in GOx specific activity found when the enzyme is free in solution or adsorbed to AuNP at varying enzyme-to-AuNP ratios. Here, GOx-AuNP conjugates that were previously found to have a dense monolayer of GOx on the surface were found to have a significantly higher specific activity than GOx free in solution. Furthermore, the more densely crowded the enzyme is on the surface, which minimizes the footprint of the enzyme to the AuNP surface, the higher the specific activity was found to be. 
A

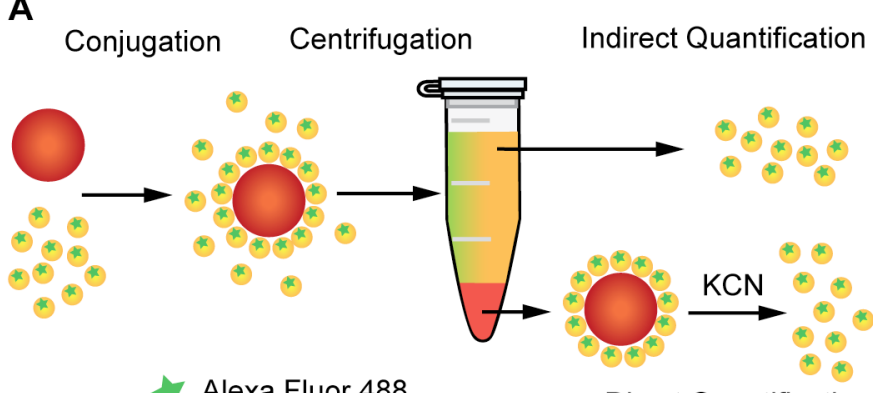

Alexa Fluor 488

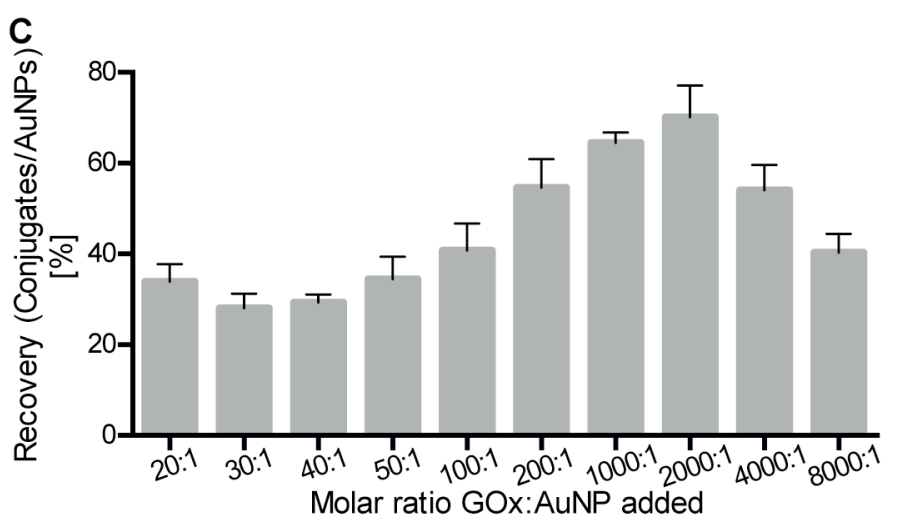

E

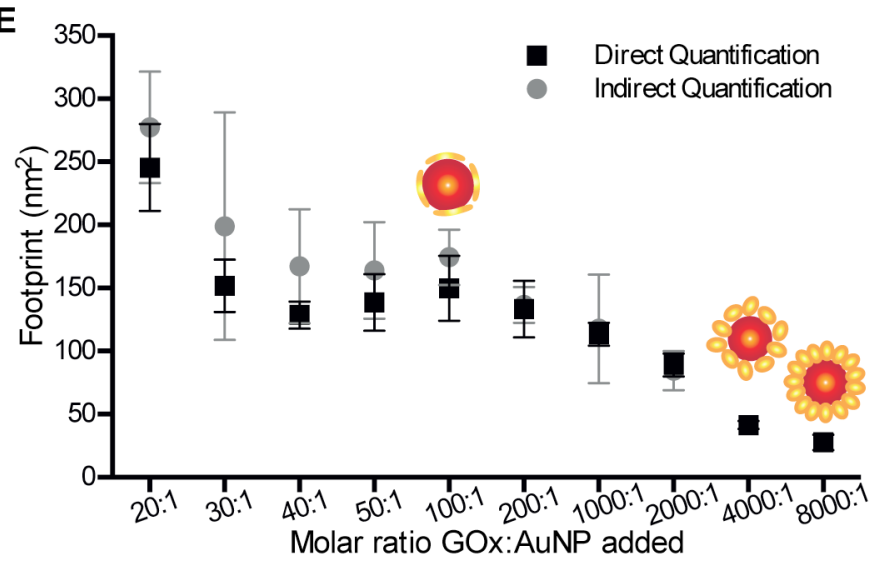

B

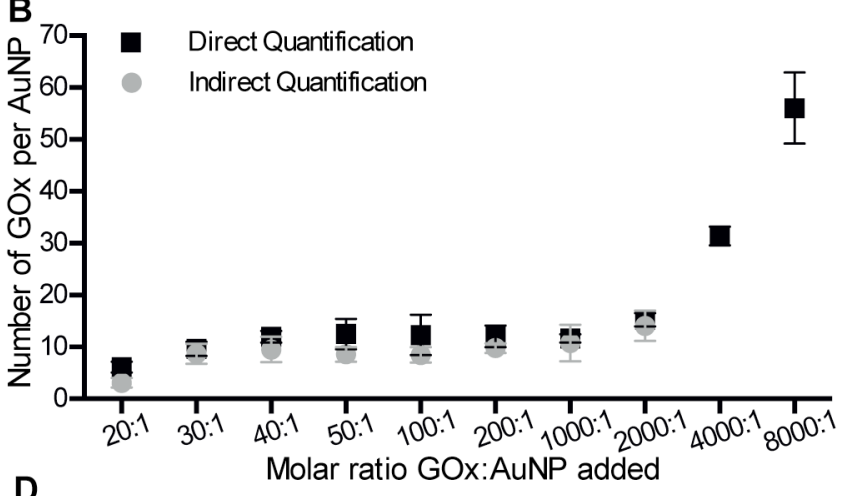

D
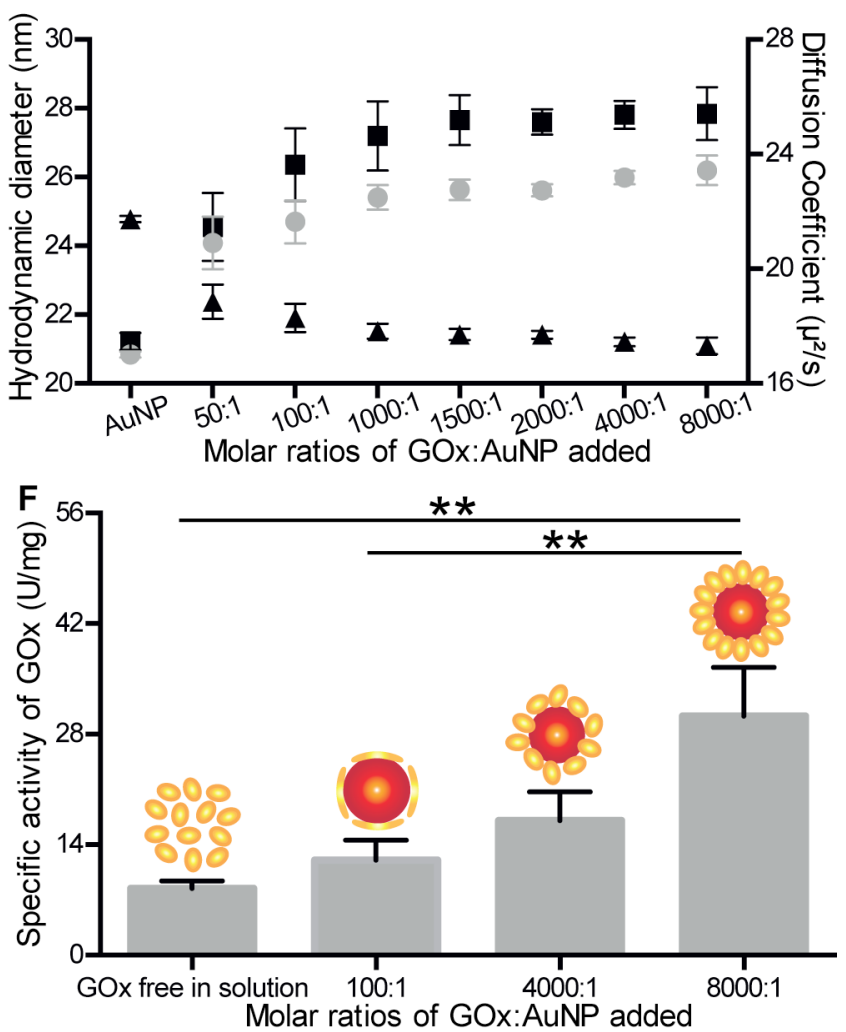

Figure 4. Quantification of GOx adsorbed per AuNP, size measurement and enzymatic activity of immobilized GOx at different adsorbing amount. (A) A schematic of experimental design for the indirect and direct fluorescent assays. For the indirect assay, the number of enzymes bound to AuNP was quantified via determination of the amount of free GOx left in the supernatant by centrifugation of the enzyme AuNP conjugate solution after the conjugation process. In the direct assay the enzyme-AuNP conjugates are subjected to KCN that dissolves AuNP, and the freed GOx to be quantified. (B) The number of GOx attached to each AuNP at adding ratios 20:1 to 8000:1 from direct (square, $\mathrm{n}=9$ ) and indirect (round, $\mathrm{n}=7-9$ ) quantification measurements. Error bars are standard error of the mean (SEM). (C) The recovery rate (\%) between obtained GOx-AuNP conjugates and AuNP added for conjugates preparation at adding ratio of GOx:AuNP from 20:1 to 8000:1, errors are SEM. (D) Determination of the hydrodynamic diameter of GOx-AuNP conjugate and $20 \mathrm{~nm}$ bare AuNP from NTA measurements (square, $\mathrm{n}=9 \sim 11$ ) and DLS measurements (round, $\mathrm{n}=9 \sim 13$, attenuation $=8$ ) with its corresponding diffusion coefficient (triangle) at room temperature. Data are shown as mean \pm standard deviation. (E) The footprint area of GOx when immobilized onto a $20 \mathrm{~nm}$ AuNP and after titrating different ratios of GOx:AuNP during conjugation, as characterized by indirect (sphere, $\mathrm{n}=7$ - 9) and direct (square, $n=9$ ) quantification measurements. (F) The specific enzymatic activity of immobilized GOx at different adding ratio of GOx:AuNP, post-hoc test after one-way ANOVA was performed to compare activity of GOx at different conditions. ${ }^{* * p}<0.01$. Data are displayed as the average $\pm \mathrm{SEM}$. Schematics are not drawn to scale.

Examination of the GOx footprint size when adsorbed onto the AuNP at different enzyme densities (Figure $4 \mathrm{E}$ ), reveals that at lower ratios of enzyme (1000:1 and below) GOx may associate with the AuNP surface in sparse densities. Compared to the reported dimensions of GOx after adsorption to flat surfaces, where enzyme flattening results in an average footprint of approximately $82 \mathrm{~nm}^{2}, 6,10-12$ and assuming that GOx here fully coats the AuNP surface, the 
measured footprint size is similar. Hence, this suggests that the enzyme has flattened at the gold colloid surface and may have lost some of its tertiary structure. Flocculation assays (Figure 3B) and measurements of the hydrodynamic diameter (Figure 4D) agree with this hypothesis as the conjugate is not induced to flocculate in the presence of a high salt concentration and the hydrodynamic diameter does not reach a maximal value without higher ratios of GOx:AuNP added during the conjugation process. At increased ratios of GOx:AuNP, conjugates were found to have higher specific activity as well as an increased number of GOx present in the monolayer of enzyme adsorbed to the AuNP surface (Figure 4B). At higher ratios, the crowding of GOx on the surface of AuNP may prevent denaturation of the tertiary structure of GOx, increase the stability of the active dimer quaternary structure of GOx, and may even optimize the orientation of GOx on the AuNP surface to enhance the likelihood of catalysis (Figure 4E,F). When creating enzymenanoparticle conjugates by adding $8000: 1$ of GOx:AuNP, the highest theoretical enzyme packing density is achieved. At this point the enzyme attaches using a minimal enzyme footprint area to the AuNP surface according to the enzyme dimensions, and we note that with this optimal enzyme packing density, the specific enzyme activity has increased by $300 \%$ in comparison to the activity of free enzyme in bulk solution (Figure 4F). This is an interesting finding considering that the high density protein molecules (i.e. GOx) in their native environment are naturally exposed to a macromolecular crowding environment and perhaps the resulted excluded volume effect is a factor that helps stabilize GOx and its catalytic properties as in live cells. ${ }^{41}$ This is in line with previous findings that GOx stabilizes or improves its activity when placed onto nanoparticle surface. ${ }^{42-44}$ An overall one-way ANOVA analysis using F-distribution was also conducted and showed a statistically significant effect of crowding degree on the specific enzymatic activity at the $p<0.005$ level for the conditions $[F(3,31)=6.5, p=0.0015]$. A follow up post-hoc test was performed to compare the difference between each group in specific enzyme activity as a function of enzyme immobilization and GOx crowding, and was presented in Figure 4F.

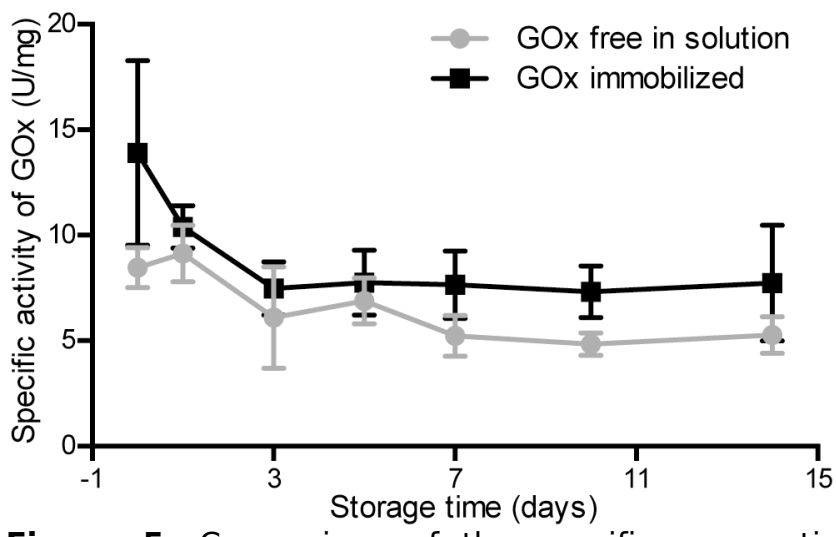

Figure 5. Comparison of the specific enzymatic activity of GOx free in solution (circles, $n=11-19$ ) and GOx immobilized to AuNP (squares, $n=10-19$ ) as a function of storage time at $4{ }^{\circ} \mathrm{C}$. Data are presented as average \pm SEM.

\section{Immobilized GOx shows comparable enzyme stability to GOX in solution.} Enzyme:AuNP conjugates have many uses in the field of bionanotechnology. In Figure $4 \mathrm{~F}$ we showed that immobilization of GOx has significantly enhanced catalytic activity over GOx in solution. The ability to store and reuse conjugates may increase their usefulness as catalytic reactors. To explore the usefulness of GOx:AuNP conjugates for this field we measured the enzymatic stability of the conjugate and GOx in solution over time to determine if immobilization of GOx may increase its longevity. As seen in Figure 5, there is a loss of enzymatic activity of both immobilized GOx and free GOx in aqueous solution over the course of 14 days of storage at $4^{\circ} \mathrm{C}$, with the immobilized GOx maintaining better stability for enzymatic activity compared to GOx in solution. A two-way repeated measures ANOVA test was performed, and the effect of storage time and immobilization condition on enzymatic activity is shown as $\mathrm{F}(6$, $109)=1.62, p=0.15$ and $F(1,109)=3.27, p=$ 0.07 , respectively. Additionally, the interaction of these two factors in their effect on the enzymatic activity is displayed as $F(6,109)=0.28, p=0.95$.

The use of monolayer coated GOx:AuNP conjugates to create an ultrafast glucose biosensor. We have previously shown with acetylcholine $^{24}$ and glutamate ${ }^{26}$ that AuNP functionalized electrodes can be used as ultrafast biosensors when coated with an optimal amount of an oxidase enzyme and rapid detections schemes for co-detection of glucose and dopamine. ${ }^{25}$ Here, we have continued that evaluation with GOx to create an ultrafast glucose sensor and test its ability to detection of glucose release by single liposome release event that occur on millisecond time scale (Figure 6A).

Biosensor efficiency was measured electrochemically using $200 \mathrm{~nm}$ liposomes filled with $200 \mathrm{mM}$ glucose. As seen in Figure 6A, glucose can be detected when the liposome lyses 
on the electrode surface releasing its contents. The glucose then is catalyzed by GOx to produce $\mathrm{H}_{2} \mathrm{O}_{2}$, which is then detected electrochemically by amperometric reduction at $-0.5 \mathrm{~V}$ at the electrode surface. An example electrochemical trace is presented in Figure 6B where each downward spike represents detection of the glucose content released from one rupturing liposome. The average spike shape from these recordings and the spike parameters used for further analysis of each detected glucose release event is presented in Figure 6C. Only files containing more than 200 spikes were analyzed $(n=6)$ and from a total of 2150 spikes examined in the 6 different trace files, the spike kinetics were $T_{1 / 2}=0.50 \pm 0.05$ $\mathrm{ms}, \mathrm{T}_{\text {rise }}=0.24 \mathrm{~ms} \pm 0.02 \mathrm{~ms}, \mathrm{~T}_{\text {fall }}=0.52 \mathrm{~ms} \pm$ $0.06 \mathrm{~ms}$ and $\mathrm{Q}=50 \mathrm{fC} \pm 10 \mathrm{fC}$ (data are shown as the mean of the means \pm SEM). A detection efficiency of $53 \% \pm 9 \%$ (average \pm SEM) determined by comparing the initial liposome concentration $(200 \mathrm{mM})$ to that found electrochemically using Equation (6) derived from Faraday's law:

$$
c_{\text {glucose, measured }}=\frac{3 Q}{4 \pi n F r^{3}}(6)
$$

where $F$ is the Faraday constant (i.e. 96485 C $\left.\mathrm{mol}^{-1}\right), \quad n \quad(n=2$ for glucose $)$ is the number of electrons transferred during the reactions, $r$ is the radius of liposome, the value of $r$ used for this calculation is from our previous study of $200 \mathrm{mM}$ glutamate liposome.

Mostly importantly, the spike kinetics showed a significant improvement of the sensor response time to the sub-millisecond timescale vesicle release events, which fits the high demands for monitoring rapid fluctuation of glucose in the biological environment for instance, in the brain.

\section{CONCLUSIONS}

We here show that by combining analytical methods to characterize how an enzyme is affected by the conjugation process in terms of shape changes upon immobilization to a $20 \mathrm{~nm}$ AuNP, the conditions to optimize enzyme stability and activity could be determined by studying the enzyme-to-AuNP surface interactions in detail. Flocculation assays were used to determine the concentration of enzyme needed in solution to achieve and control the coating of GOx to a monolayer coverage at the AuNP surface, while the indirect and direct fluorescent quantification assays was used to confirm the enzyme densities at the AuNP surface after the conjugation process.

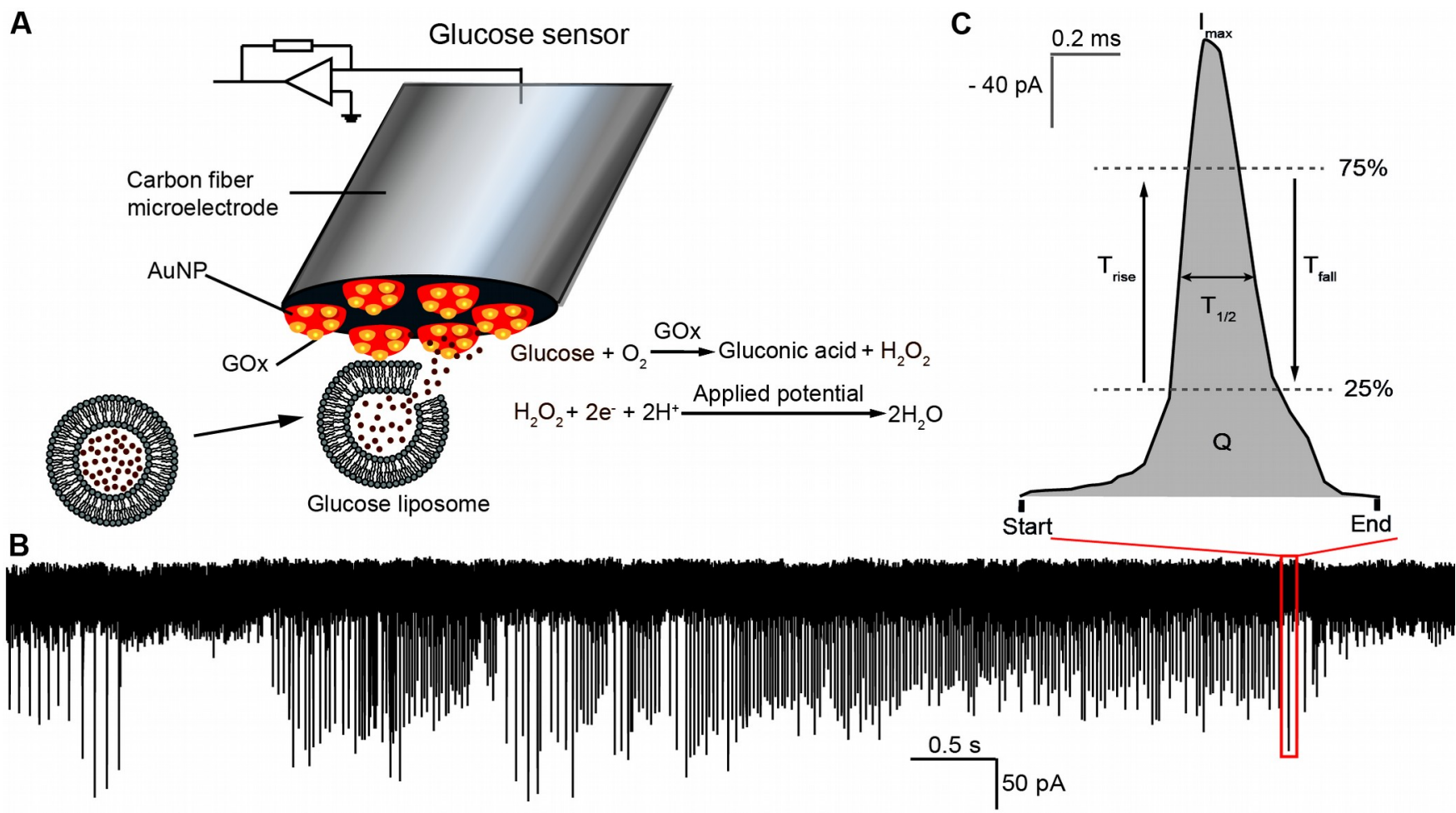

Figure 6. Ultrafast detection of glucose transients. (A) Illustration of the design of an amperometric glucose microsensor constructed by placing a GOx monolayer at the surface of a AuNP modified carbon fiber microelectrode and showing the spontaneous rupture of glucose-filled liposomes at the sensor surface in response to the applied electrode redox potential, which is used for detection of hydrogen peroxide serving as the reporting molecule for glucose. Schematics are not drawn to scale. (B) Trace of amperometric response of glucose release from liposomes bursting at the electrode surface when applying a $-500 \mathrm{mV}$ potential vs a $\mathrm{Ag} / \mathrm{AgCl}$ reference electrode. (C) A representative current spike corresponding to detection of a glucose release from a single liposome and marked with parameters of current spike dynamics used for current spike analysis. $T_{1 / 2}$ is the time width at the half maximum current peak amplitude, $T_{\text {rise }}$ and $T_{\text {fall }}$ are the current rise and fall 
time marked between $25 \%$ and $75 \%$ of the peak amplitude, $I_{\max }$ is the maximum peak amplitude, $\mathrm{Q}$ is the charge detected at each current peak.

At the lower enzyme concentrations used for conjugation, the GOx were spreading thin and creating larger foot prints at the AuNP surface, while at higher enzyme concentrations provided smaller foot prints and at the most molecularly crowded conditions the enzyme footprint was minimized down to the size indicating tightly packed short-end bound enzymes. The direct and indirect fluorescent quantification assays showed that the number of enzymes bound to the surface of single $20 \mathrm{~nm}$ AuNPs increased from about 10 up to 50 , when varying the conjugation ratio of GOx:AuNP from 50:1 up to $8000: 1$. This fits the theoretical calculations of forming all from a sparse to a dense monolayer of enzyme covering the AuNP surface. The DLS and NTA experiments confirmed that when adding higher GOx:AuNP ratios from 1000:1 to 8000:1 during conjugation, the resulting size of GOx-AuNP conjugates remained constant supporting that a monolayer of GOx is covering the AuNP's surface. These results imply that packing the enzymes tight at the highly curved surface of $20 \mathrm{~nm}$ AuNP help to diminish structure deformation of GOx compared to when the enzyme bind to a flat solid surface. In addition and most importantly, the highest enzyme packing densities formed, where the enzyme is forced into a minimal space and attached by a minimal footprint to the AuNP surface, the specific enzyme activity is improved about $300 \%$ versus enzyme activity in bulk solution. The careful examination of the GOx:AuNP interaction has shown how immobilization and crowding conditions can affect the activity of a biomolecule. For GOx this characterization has culminated in the optimization of an ultrafast glucose biosensor in which the enhanced enzymatic activity and stability led to the detection of individual liposomes similar in size to some secretory vesicles. Hence, provides a sensing technology that is fast enough by orders of magnitude to monitor physiological relevant fluctuations of glucose in the brain, which is of great importance for monitoring brain metabolism coupled to healthy and disease state of the brain.

\section{AUTHOR INFORMATION}

\section{Corresponding Author}

* Email: cans@chalmers.se

\section{Notes}

The authors declare no competing financial interest.

\section{ACKNOWLEDGMENT}

We acknowledge the funding from The Swedish Research Council and The Chalmers Areas of Advance Nanoscience and Nanotechnology.

\section{REFERENCES}

(1) Physical Chemistry of Biological Interface; Baszkin, A., Norde, W., Eds.; Marcel Dekker, Inc.: New York, 1999.

(2) Copeland, R. A. Enzymes, 2nd ed.; John Wiley \& Sons, Inc.: New York, USA, 2000.

(3) Wilson, R.; Turner, A. P. F. Glucose Oxidase: An Ideal Enzyme. Biosens. Bioelectron. 1992, 7, 165-185.

(4) Hecht, H. J.; Kalisz, H. M.; Hendle, J.; Schmid, R. D.; Schomburg, D. Crystal Structure of Glucose Oxidase from Aspergillus Niger Refined at 2.3 $\AA$ Reslution. J. Mol. Biol. 1993, 229, 153-172.

(5) Hayashi, S.; Koga, K. Effect of Periodate Oxidation on the Structure and Properties of Glucose Oxidase. Biochim. Biophys. Acta 1976, 445, 294-308.

(6) Szucs, A.; Hitchens, G. D.; Bockris, J. O. On the Adsorption of Glucose Oxidase at a Gold Electrode. J. Electrochem. Soc. 1989, 136, 3748-3755.

(7) Hecht, H. J.; Schomburg, D.; Kalisz, H.; Schmid, R. D. The $3 d$ Structure of Glucose-Oxidase from Aspergillus-Niger - Implications for the Use of God as a Biosensor Enzyme. Biosens. Bioelectron. 1993, 8, 197203.

(8) Fan, F.-R. F.; Bard, A. J. Imaging of Biological Macromolecules on Mica in Humid Air by Scanning Electrochemical Microscopy. Proc. Natl. Acad. Sci. U. S. A. 1999, 96, 14222-14227.

(9) Kamyshny, A.; Danino, D.; Magdassi, S.; Talmon, Y. Transmission Electron Microscopy at Cryogenic Temperatures and Dynamic Light Scattering Studies of Glucose Oxidase Molecules and Self-Aggregated Nanoparticles. Langmuir 2002, 18, 3390-3391.

(10) Otsuka, I.; Yaoita, M.; Nagashima, S.; Higano, M. Molecular Dimensions of Dried Glucose Oxidase on a Au(l 11 1) Surface Studied by Dynamic Mode Scanning Force Microscopy. Electrochim. Acta 2005, 50, 48614867.

(11) Czajka, R.; Koopal, C. G. J.; Feiters, M. C.; Gerritsen, J. W.; Nolte, R. J. M.; Van Kempen, H. Scanning Tunnelling Microscopy Study of Polypyrrole Films and of Glucose Oxidase as Used in a ThirdGeneration Biosensor. Bioelectrochemistry Bioenerg. 1992, 29, 47-57.

(12) Cullen, D. C.; Lowe, C. R. AFM Studies of Protein Adsorption: 1. Time-Resolved Protein Adsorption to Highly Oriented Pyrolytic Graphite. J. Colloid Interface Sci. 1994, 166, 102-108.

(13) Vertegel, A. A.; Siegel, R. W.; Dordick, J. S. Silica Nanoparticle Size Influences the Structure and Enzymatic Activity of Adsorbed Lysozyme. Langmuir 2004, 20, 6800-6807.

(14) Cans, A. S.; Dean, S. L.; Reyes, F. E.; Keating, C. D. Synthesis and Characterization of Enzyme-Au Bioconjugates: HRP and Fluorescein-Labeled HRP. Nanobiotechnology 2007, 3, 12-22.

(15) Thörn, C.; Gustafsson, H.; Olsson, L. Immobilization of Feruloyl Esterases in Mesoporous Materials Leads to Improved Transesterification Yield. J. Mol. Catal. B Enzym. 2011, 72, 57-64.

(16) Lei, C.; Soares, T. a; Shin, Y.; Liu, J.; Ackerman, E. J. Enzyme Specific Activity in Functionalized Nanoporous Supports. Nanotechnology 2008, 19, 125102. 
(17) Lei, C.; Shin, Y.; Magnuson, J. K.; Fryxell, G.; Lasure, L. L.; Elliott, D. C.; Liu, J.; Ackerman, E. J. Characterization of Functionalized Nanoporous Supports for Protein Confinement. Nanotechnology 2006, 17, 5531-5538.

(18) Caruso, F.; Schüler, C. Enzyme Multilayers on Colloid Particles: Assembly, Stability, and Enzymatic Activity. Langmuir 2000, 16, 9595-9603.

(19) Haupt, B.; Neumann, T.; Wittemann, A.; Ballauff, M. Activity of Enzymes Immobilized in Colloidal Spherical Polyelectrolyte Brushes. Biomacromolecules 2005, 6, 948-955.

(20) Wu, H.; Wang, J.; Kang, X.; Wang, C.; Wang, D.; Liu, J.; Aksay, I. A.; Lin, Y. Glucose Biosensor Based on Immobilization of Glucose Oxidase in Platinum Nanoparticles/Graphene/Chitosan Nanocomposite Film. Talanta 2009, 80, 403-406.

(21) Devasenathipathy, R.; Mani, V.; Chen, S. M.; Huang, S. T.; Huang, T. T.; Lin, C. M.; Hwa, K. Y.; Chen, T. Y.; Chen, B. J. Glucose Biosensor Based on Glucose Oxidase Immobilized at Gold Nanoparticles Decorated Graphene-Carbon Nanotubes. Enzyme Microb. Technol. 2015, 78, 40-45.

(22) Periasamy, A. P.; Umasankar, Y.; Chen, S. M. Nanomaterials - Acetylcholinesterase Enzyme Matrices for Organophosphorus Pesticides Electrochemical Sensors: A Review. Sensors 2009, 9, 4034-4055.

(23) Kergoat, L.; Piro, B.; Simon, D. T.; Pham, M. C.; Noël, V.; Berggren, M. Detection of Glutamate and Acetylcholine with Organic Electrochemical Transistors Based on Conducting Polymer/Platinum Nanoparticle Composites. Adv. Mater. 2014, 26, 5658-5664.

(24) Keighron, J. D.; Wigström, J.; Kurczy, M. E.; Bergman, J.; Wang, Y.; Cans, A.-S. Amperometric Detection of Single Vesicle Acetylcholine Release Events from an Artificial Cell. ACS Chem. Neurosci. 2015, 6, 181-188.

(25) Bergman, J.; Mellander, L.; Wang, Y.; Cans, A.-S. Co-Detection of Dopamine and Glucose with High Temporal Resolution. Catalysts 2018, 8, 34.

(26) Wang, Y.; Mishra, D.; Bergman, J.; Keighron, J. D.; Skibicka, K. P.; Cans, A.-S. Ultrafast Glutamate Biosensor Recordings in Brain Slices Reveal Complex Single Exocytosis Transients. ACS Chem. Neurosci. 2019, 10, 1744-1752.

(27) Clay, M.; Monbouquette, H. G. A Detailed Model of Electroenzymatic Glutamate Biosensors To Aid in Sensor Optimization and in Applications in Vivo. ACS Chem. Neurosci. 2018, 9, 241-251.

(28) Bankar, S. B.; Bule, M. V.; Singhal, R. S.; Ananthanarayan, L. Glucose Oxidase - An Overview. Biotechnol. Adv. 2009, 27, 489-501.

(29) Calvo, E. J.; Etchenique, R. a.; Pietrasanta, L.; Wolosiuk, A. Layer-By-Layer Self-Assembly of Glucose Oxidase and Os(Bpy)2ClPyCH2NH-Poly(Allylamine) Bioelectrode. Anal. Chem. 2001, 73, 1161-1168.

(30) Franco, R.; Pereira, E. Gold Nanoparticles and Proteins, Interaction. In Encyclopedia of Metalloproteins; Kretsinger, R. H., Uversky, V. N.,
Permyakov, E. A., Eds.; Springer New York: New York, NY, 2013; pp 908-915.

(31) Toma, H. E.; Zamarion, V. M.; Toma, S. H.; Araki, K. The Coordination Chemistry at Gold Nanoparticles. J. Braz. Chem. Soc 2010, 21, 1158-1176.

(32) Frederick, K. R.; Tung, J.; Emerick, R. S.; Masiarz, F. R.; Chamberlain, S. H.; Vasavada, A.; Rosenberg, S.; Chakraborty, S.; Schopfer, L. M.; Massey, V. Glucose Oxidase from Aspergillus Niger. Cloning, Gene Sequence, Secretion from Saccharomyces Cerevisiae and Kinetic Analysis of a Yeast-Derived Enzyme. J Biol Chem 1990, 265, 3793-3802.

(33) Keighron, J. D.; Keating, C. D. Enzyme-Gold Nanoparticle Bioconjugates: Quantification of Particle Stoichiometry and Enzyme Specific Activity; Rosenthal, J. S., Wright, W. D., Eds.; Humana Press: Totowa, NJ, 2013; pp 163-174.

(34) Haiss, W.; Thanh, N. T. K.; Aveyard, J.; Fernig, D. G. Determination of Size and Concentration of Gold Nanoparticles from UV-Vis Spectra. Anal. Chem. 2007, 79, 4215-4221.

(35) Nicol, M. J.; Duke, F. R. Substrate Inhibition with Glucose Oxidase. J. Biol. Chem. 1966, 241, 4292-4293.

(36) Reed, M. C.; Lieb, A.; Nijhout, H. F. The Biological Significance of Substrate Inhibition: A Mechanism with Diverse Functions. BioEssays 2010, 32, 422-429.

(37) Yoshino, M.; Murakami, K. Analysis of the Substrate Inhibition of Complete and Partial Types. Springerplus 2015, 4, 292.

(38) Mayer, L. D.; Hope, M. J.; Cullis, P. R.; Janoff, A. S. Solute Distributions and Trapping Efficiencies Observed in Freeze-Thawed Multilamellar Vesicles. Biochim. Biophys. Acta - Biomembr. 1985, 817, 193-196.

(39) Finot, M. O.; Braybrook, G. D.; Mcdermott, M. T. Characterization of Electrochemically Deposited Gold Nanocrystals on Glassy Carbon Electrodes. J. Electroanal. Chem. 1999, 466, 234-241.

(40) Mosharov, E. V; Sulzer, D. Analysis of Exocytotic Events Recorded by Amperometry. Nat. Methods 2005, 2,651 .

(41) Zhou, H.-X.; Rivas, G.; Minton, A. P. Macromolecular Crowding and Confinement: Biochemical, Biophysical, and Potential Physiological Consequences. Annu. Rev. Biophys. 2008, 37, 375-397.

(42) Abbasi, M.; Amiri, R.; Bordbar, A.-K.; Ranjbakhsh, E.; Khosropour, A.-R. Improvement of the Stability and Activity of Immobilized Glucose Oxidase on Modified Iron Oxide Magnetic Nanoparticles. Appl. Surf. Sci. 2016, 364, 752-757.

(43) Kojima, S.; Nagata, F.; Inagaki, M.; Kugimiya, S.; Kato, K. Enzyme Immobilisation on Poly- $<s c p>\mid</ S c p>$ -Lysine-Containing Calcium Phosphate Particles for Highly Sensitive Glucose Detection. RSC Adv. 2019, 9 10832-10841.

(44) Rossi, L. M.; Quach, A. D.; Rosenzweig, Z. Glucose Oxidase?Magnetite Nanoparticle Bioconjugate for Glucose Sensing. Anal. Bioanal. Chem. 2004, 380, 606-613. 
TABLE OF CONTENT

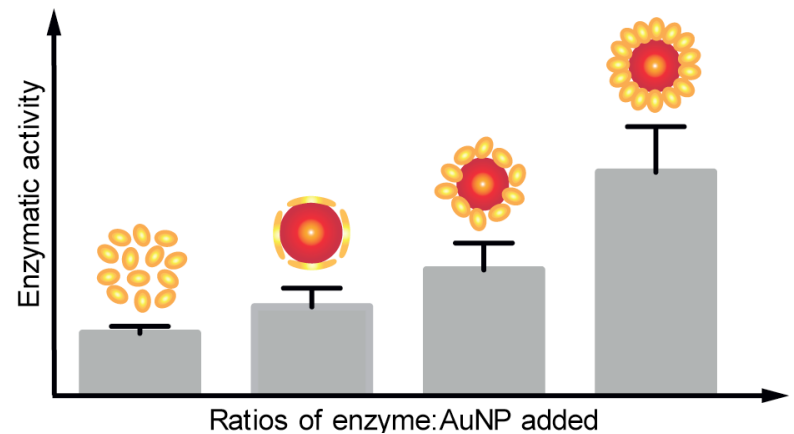

